\title{
TEORES DE NUTRIENTES FOLIARES EM PLANTAS DE ERVA-MATE EM FUNÇÃO DA POSIÇÃO E ORIENTAÇÃO GEOGRÁFICA DA COPA, EM GUARAPUAVA-PR ${ }^{1}$
}

\author{
LEAF NUTRIENT CONTENTS IN Ilex paraguariensis TREE CONSIDERING \\ CANOPY POSITION AND GEOGRAPHICAL ORIENTATION, IN GUARAPUAVA- \\ $P R$
}

\author{
Jorge Luiz Moretti de SOUZA² \\ Marla Alessandra de $\mathrm{ARAUJO}^{3}$ \\ Carlos Bruno REISSMANN ${ }^{4}$ \\ Agenor MACCARI JÚNIOR ${ }^{5}$ \\ Clauriane Stele WOLF ${ }^{3}$
}

\begin{abstract}
RESUMO
O objetivo do presente trabalho consistiu em analisar a relação massa seca e fresca e os teores de N, P, K, Ca e Mg das folhas de plantas de erva-mate (llex paraguariensis St. Hil.), em função da posição (terços: inferior, médio e superior) e orientação geográfica (norte, sul, leste e oeste) da copa. O experimento foi realizado em Guarapuava-PR, em um plantio (erval) com 15 anos de idade. As análises evidenciaram que: a relação média entre a massa seca e fresca nos terços ficou em 0,4463; com exceção do cálcio, verificou-se que as plantas de erva-mate não exportam diferentes quantidades do nutriente em relação à posição da copa e orientação geográfica; $35,45 \%$ das folhas de erva-mate encontram-se no terço inferior, $36,84 \%$ no terço médio e $27,71 \%$ no terço superior; as concentrações totais dos nutrientes ( $\mathrm{N}, \mathrm{P}, \mathrm{K}, \mathrm{Ca}$ e $\mathrm{Mg}$ ) obtidos nas folhas da erva-mate foram menores do que os encontrados em ervais nativos do Paraná.
\end{abstract}

Palavras-chave: análise química; teores; macronutrientes.

\begin{abstract}
The objective of this paper was to analyze the relation between dry and fresh weight and the nutrient contents $(\mathrm{N}$, $\mathrm{P}, \mathrm{K}, \mathrm{Ca}$ e $\mathrm{Mg}$ ) in leafs of Ilex paraguariensis tree, considering canopy position (lower, medium and upper) and geographical orientation (north, south, east and west). The experiment was accomplished in Guarapuava-PR, in a stand with 15 years of age. The analyses showed that: the medium relationship among the dry and fresh weight of leaves in the canopy position was in 0,4463; except for the calcium, the llex Paraguariensis trees do not export different amounts of the nutrient in relation to the canopy position and geographical orientation; $35,45 \%$ of the leaves are in the lower canopy position, $36,84 \%$ in the medium and $27,71 \%$ in the upper; the concentrations of the nutrients $(\mathrm{N}, \mathrm{P}, \mathrm{K}, \mathrm{Ca}$ and $\mathrm{Mg}$ ) found in the leaves were smaller than values verified in native llex paraguariensis trees.
\end{abstract}

Key-words: chemical analysis; contents; macronutrients.

\footnotetext{
1 Trabalho desenvolvido como parte de Dissertação de Mestrado na UFPR.

${ }^{2}$ Engenheiro Agrícola, Doutor em Agronomia, Professor do Departamento de Solos e Engenharia Agrícola, Setor de Ciências Agrárias, Universidade Federal do Paraná (DSEA/SCA/UFPR). Rua dos Funcionários, 1540. Cep 80035-050, Curitiba, PR, Brasil. E-mail: jmoretti@ufpr.br. Autor para correspondência;

${ }^{3}$ Engenheira Agrônoma, Mestranda do Programa de Pós-Graduação em Ciência do Solo da UFPR, bolsista CNPq.

${ }^{4}$ Engenheiro Florestal, Doutor em Nutrição Florestal, Professor Sênior do DSEA / SCA / UFPR.

${ }^{5}$ Engenheiro Agrônomo, Doutor em Tecnologia Pós-Colheita, Professor do DSEA / SCA / UFPR.
} 
SOUZA, J.L.M. et al. Teores de nutrientes foliares em plantas...

\section{INTRODUÇÃO}

Apesar de ser uma das atividades mais antigas na região sul do país, como ocorre com várias espécies nativas, a erva-mate é carente em informações e pesquisas sobre o seu correto cultivo. REISSMANN et al. (1983) e LOURENÇO et al. (1997) comentam que a cultura da erva-mate, tendo suas folhas como produto, é grande exportadora de nutrientes dos campos de produção. FOSSATI (1997) observando teores médios de K, $\mathrm{Ca}$ e $\mathrm{Mg}$ nos tecidos de erva-mate em plantio comercial, também comenta que existem poucas informações sobre as quantidades de nutrientes de reposição e adubação para esta cultura, visto que ela sofre variação nos teores dos elementos em relação a sua idade, sanidade e estações do ano. REISSMANN et al. (1983) recomendam que a exportação de nutrientes através da colheita, a qual consiste basicamente na poda de ramos, deve ser compensada mediante a quantificação da biomassa exportada e da determinação do conteúdo de nutrientes nela existente, visando manter a capacidade produtiva da cultura.

Os teores de nutrientes são específicos não somente para a espécie, idade e tecido, como também, dependem do ambiente. Diversos fatores controlam o teor de elementos nos vegetais, principalmente 0 genético (ANDRAE e KRAPFENBAUER, 1983; MALAVOLTA, 1980). Conforme ZÖTTL (1973), com exceção dos frutos, são as folhas que detém o maior teor de nutrientes.

A análise química foliar consiste na determinação dos teores de elementos em tecidos vegetais (principalmente folhas) visando 0 diagnóstico do estado nutricional da cultura. Vários casos de deficiência e toxidez de nutrientes em plantas podem ser identificados mediante a utilização da técnica de análise foliar. Esta técnica propicia o conhecimento do estado nutricional da cultura, auxilia na interpretação dos efeitos residuais de adubações já efetuadas e, também, ajuda estimar indiretamente, o grau de fertilidade do solo. Permite ainda, distinguir sintomas provocados por agentes patogênicos decorrentes de uma nutrição inadequada (TRANI et al., 1983).

Dentro dos diferentes temas abordados pela nutrição florestal, a literatura contempla diversos trabalhos que tratam da variação dos teores de nutrientes nas folhas de erva-mate ao longo do ano. Porém, são escassas informações sobre a extração de nutrientes considerando diferentes partes da copa (terços) da planta dessa espécie. VAN DEN DRIESSCHE (1984) comenta que a idade das folhas afeta a distribuição de nutrientes em função da redistribuição dos nutrientes móveis para outros órgãos, como folhas novas, órgãos de reserva e regiões de crescimento, antes da abcissão ou eventual corte mecânico.

Outro ponto importante a ser considerado refere-se à exposição dos ervais, ou seja, a pleno sol ou sombreados. Segundo TAIZ e ZEIGER (2004) e FOSSATI (1997), a luz incidente representa estímulo às plantas de modo geral, promovendo alterações morfológicas e em seus processos fisiológicos, atuando diretamente sobre a síntese, teor e degradação de metabólitos vegetais. REISSMANN et al. (1994) e OLIVA (2007) também estudaram a exposição dos ervais a pleno sol, os quais avaliaram o estado nutricional da cultura da erva-mate realizando coletas no terço médio da face de exposição norte da copa.

Mediante as colocações dispostas nos parágrafos anteriores, verifica-se a necessidade de avanços nos estudos com a cultura da erva-mate, a fim de unir conhecimentos e interpretar dados com mais exatidão, para que o setor ervateiro possa se desenvolver com a qualidade dos produtos seguindo a tendência do mercado atual.

O objetivo do presente trabalho consistiu em analisar a relação massa seca e fresca e as possíveis variações dos teores de nutrientes $(N, P$, $\mathrm{K}, \mathrm{Ca}$ e $\mathrm{Mg}$ ) das folhas de plantas de erva-mate (Ilex paraguariensis St. Hil.), em função da posição da copa amostrada (terços: inferior, médio e superior) e da face de exposição dos terços (orientação geográfica: norte, sul, leste e oeste).

\section{MATERIAL E MÉTODOS}

O presente trabalho corresponde a uma etapa no desenvolvimento de um projeto de pesquisa que ao seu término visa determinar a exportação de nutrientes $(\mathrm{N}, \mathrm{P}, \mathrm{K}, \mathrm{Ca}$ e $\mathrm{Mg}$ ) realizada pelas plantas de erva-mate (llex paraguariensis St. Hil.) em função de diferentes sistemas de poda, quantificar a adubação necessária para mantê-las sustentavelmente ao longo do tempo e identificar o sistema de poda mais viável economicamente.

O experimento foi instalado e conduzido em área pertencente à Fazenda São José, situada na Serra da Esperança, município de Guarapuava-PR, a 25 23' 36" de latitude sul, 5127'19" de longitude oeste, $1120 \mathrm{~m}$ de altitude e $286 \mathrm{~km}$ de Curitiba. Segundo classificação climática de Köppen, o clima da região é do tipo $\mathrm{Cfb}$, e o solo pertence à classe Latosssolo Bruno Álico (EMBRAPA, 1999).

A Fazenda São José tem como atividade principal a exploração da erva-mate, possuindo ervais nativos e cultivados a pleno sol, perfazendo uma população total de aproximadamente um milhão de plantas. O projeto visa estimar técnica e economicamente a exportação de nutrientes em plantas de erva-mate em função de diferentes tipos de poda.

O talhão utilizado para retirar as amostras experimentais encontra-se em fase produtiva e foi implantado em 1988, em área a pleno sol. O espaçamento utilizado foi o de $2 \times 3 \mathrm{~m}$ (entre plantas $x$ entre linhas).

A área experimental possui um delineamento experimental de 3 blocos, 5 tratamentos e 12 repetições. Cada bloco possui 6 $\mathrm{m}$ de largura por $12 \mathrm{~m}$ de comprimento, compreendendo uma área de $72 \mathrm{~m}^{2}$, adicionada uma fileira de árvores de erva-mate como bordadura. 
O delineamento estatístico foi de parcelas subdivididas, contendo três tratamentos, quatro subtratamentos e três repetições (blocos). Cada repetição consistiu-se de uma planta de erva-mate em fase produtiva, escolhida aleatoriamente entre as plantas testemunhas que não sofreram poda, e que se encontravam entre os blocos do delineamento experimental do projeto. As plantas

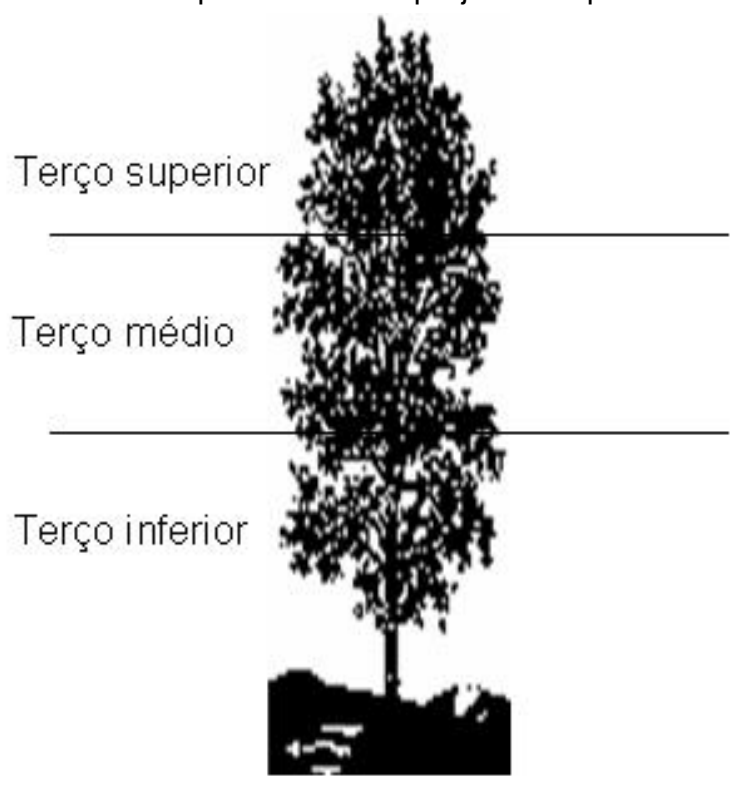

(a) selecionadas apresentavam homogeneidade quanto à altura e volume das folhas. Cada tratamento ou parcela foi representado por um terço (inferior, médio e superior) e os sub-tratamentos representados por uma posição geográfica (norte, sul, leste e oeste), conforme pode ser observado na Figura 1.

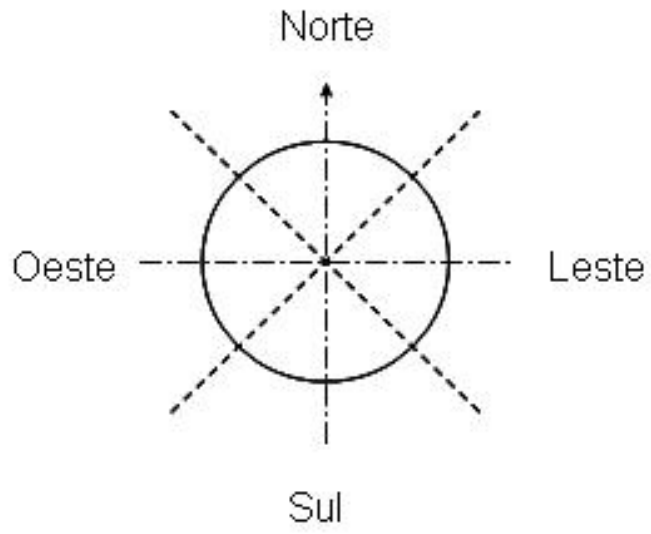

(b)

FIGURA 1 - Esquema contendo: (a) Terços (inferior, médio e superior) e (b) orientação geográfica (norte, sul, leste e oeste) das plantas de erva-mate do experimento.

As análises estatísticas foram realizadas conforme recomendações de GOMES (2000), utilizando-se o programa "Sirichai's Statistcs"versão 3.0 (1987). Os dados obtidos para os nutrientes, em função dos terços e posição geográfica das plantas, foram submetidos a uma análise de variância e teste de Duncan para comparação de médias. Uma planilha eletrônica foi utilizada para armazenar e organizar os dados. Os trabalhos de campo na área experimental envolveram os seguintes passos:

- Com o auxílio de uma bússola, identificouse e marcou os quadrantes (norte, sul, leste e oeste) de três plantas de erva-mate. A marcação dos quadrantes correspondeu às quatro posições geográficas de interesse;

- Os quadrantes mencionados foram marcados com fitas coloridas estabelecendo-se o local da coleta das folhas para cada posição geográfica. As folhas foram coletadas respeitando os quadrantes médios apresentados na bússola (Figura 1b);

- Com o auxilio de um metro e fitas, marcouse também a altura dos terços inferior, médio e superior da copa das três árvores de erva-mate. A denominação terço inferior corresponde à altura entre a base da copa até $1 / 3$ da altura da mesma, a denominação terço médio corresponde à altura entre
$1 / 3$ e 2/3 da altura da copa, e a denominação terço superior corresponde a $2 / 3$ da altura da copa até o ápice da planta (Figura 1a);

- Posteriormente coletou-se todo o material necessário. A coleta das plantas e amostragem das folhas foi realizada na época de poda, ou seja, no inverno antes de ocorrer a nova brotação. As folhas estavam maduras e a erveira estava em repouso fisiológico;

- Após a realização das atividades de campo, o material colhido foi acondicionado em embalagens plásticas, devidamente identificado e levado ao Laboratório de Tecnologia de Produtos Agrícolas / DSEA / SCA / UFPR. Posteriormente, seguindo a metodologia proposta por REISSMANN et al. (1985), coletou-se uma amostra de 100 folhas para cada planta, terço e orientação geográfica, totalizando 1200 folhas por árvore;

- No laboratório, as amostras de 100 folhas por planta, terços e orientação geográfica, tiveram a massa fresca determinada. Em seguida, as mesmas foram colocadas em sacos de papel e secas em estufa tipo Bipolar à $60{ }^{\circ} \mathrm{C}$, onde permaneceram por um período de três semanas até atingirem massa constante. A massa fresca e seca foi determinada em uma balança do tipo Instrutherm (500 g x 0,1 g);

- Após a tomada da massa fresca e seca 
das amostras, as mesmas foram trituradas e encaminhadas para o Laboratório de Biogeoquímica e Nutrição de Plantas / DSEA / SCA / UFPR, para determinação dos teores de N, P, K, Ca e Mg existente nos diferentes terços da copa e da orientação geográfica de cada planta;

- A determinação dos teores de Ca e Mg foi realizada pelo método de absorção atômica. A de $\mathrm{K}$ foi feita por emissão, seguindo as recomendações de PERKIN (1976). As de $\mathrm{N}$ foram realizadas utilizando-se o método de Kjeldahl, conforme recomendação de BREMER (1960). A do P foi feita segundo a metodologia proposta por EMBRAPA (1997). Para a obtenção dos extratos para a leitura do $\mathrm{P}, \mathrm{K}, \mathrm{Ca}$ e $\mathrm{Mg}$, as amostras foram submetidas à digestão via seca, em mufla, a $500^{\circ} \mathrm{C}$, e solubilizado posteriormente em $\mathrm{HCl} 3 \mathrm{~mol} \mathrm{~L}^{-1}$.

\section{RESULTADOS E DISCUSSÃO}

A Tabela 1 apresenta os resultados da massa fresca (MF), seca (MS), relação entre a massa seca e fresca (MS/MF), massa média de água (MMA) e massa fresca média (MFM) de 100 folhas de erva-mate, para cada planta (I, II e III), terço da copa (inferior, médio e superior) e orientação geográfica (norte, sul, leste e oeste) de interesse. Estes resultados permitem verificar que a relação média entre a massa seca e fresca das folhas de erva-mate, considerando-se apenas a altura, apresentou valores semelhantes, sendo 0,4499 para o terço inferior, 0,4430 para o terço médio e 0,4460 para o terço superior. O valor médio da relação massa seca/fresca para os três terços ficou em 0,4463 . Desta forma, verifica-se que $100 \mathrm{~kg}$ de massa fresca de folhas de erva-mate apresentam, em média, 44,63 $\mathrm{kg}$ de massa seca de folhas e $55,37 \mathrm{~kg}$ de água. Os resultados encontrados para a relação massa seca/fresca estão de acordo com os obtidos por MACCARI JÚNIOR (2005), que em um diagnóstico do pré-processamento da erva-mate no Estado do Paraná, obteve uma relação massa seca/fresca igual a 0,4069, 0,4220, 0,4200, 0,4020 e 0,4407 , respectivamente, para os secadores tipo esteira, rotativos, fixo com misturador, rotativo e leiro fixo (carijó).

TABELA 1 - Média da massa fresca (MF) e seca (MS), relação entre a média da massa seca e fresca (MS/MF), massa média de água (MMA) e massa fresca média (MFM) em 100 folhas de erva-mate (Ilex paraguariensis), coletadas em função dos terços e orientação geográfica.

\begin{tabular}{|c|c|c|c|c|c|c|c|c|}
\hline \multirow{2}{*}{ Orientação } & \multirow{2}{*}{ Terço } & \multirow{2}{*}{$\begin{array}{l}\text { MF } \\
(g)\end{array}$} & \multirow{2}{*}{$\begin{array}{r}\text { MS } \\
(\mathrm{g})\end{array}$} & \multirow{2}{*}{$\begin{array}{c}\mathrm{MS} / \mathrm{MF} \\
-\end{array}$} & \multicolumn{2}{|c|}{----- MMA ----- } & \multicolumn{2}{|c|}{----- MFM ----- } \\
\hline & & & & & (g) & $(\%)$ & $(\mathrm{kg})$ & $(\%)$ \\
\hline Norte & Inferior & 77,7 & 37,1 & 0,4775 & 40,6 & 52,3 & 1,07 & 14,17 \\
\hline \multirow{2}{*}{ médio } & Médio & 84,8 & 36,2 & 0,4269 & 48,6 & 57,3 & 0,60 & 8,24 \\
\hline & Superior & 72,5 & 32,6 & 0,4497 & 39,9 & 55,0 & 0,70 & 9,46 \\
\hline \multirow{3}{*}{$\begin{array}{c}\text { Sul } \\
\text { médio }\end{array}$} & Inferior & 79,5 & 35,4 & 0,4453 & 44,1 & 55,5 & 0,50 & 6,44 \\
\hline & Médio & 83,0 & 38,0 & 0,4578 & 45,0 & 54,2 & 0,63 & 8,80 \\
\hline & Superior & 71,7 & 31,2 & 0,4351 & 40,5 & 56,5 & 0,57 & 7,31 \\
\hline \multirow{3}{*}{$\begin{array}{l}\text { Leste } \\
\text { médio }\end{array}$} & Inferior & 84,3 & 37,6 & 0,4460 & 46,7 & 55,4 & 0,60 & 7,18 \\
\hline & Médio & 87,3 & 39,3 & 0,4502 & 48,0 & 55,0 & 0,53 & 7,65 \\
\hline & Superior & 61,5 & 27,9 & 0,4537 & 33,6 & 54,6 & 0,50 & 6,01 \\
\hline \multirow{3}{*}{$\begin{array}{l}\text { Oeste } \\
\text { médio }\end{array}$} & Inferior & 79,4 & 34,2 & 0,4307 & 45,2 & 56,9 & 0,70 & 7,66 \\
\hline & Médio & 84,9 & 37,1 & 0,4370 & 47,8 & 56,3 & 0,90 & 12,15 \\
\hline & Superior & 60,6 & 27,0 & 0,4455 & 33,6 & 55,4 & 0,43 & 4,94 \\
\hline \multicolumn{2}{|c|}{ Soma do terço inferior } & 320,9 & 144,3 & 0,4499 & 176,6 & 55,0 & 2,87 & 35,45 \\
\hline \multicolumn{2}{|c|}{ Soma do terço médio } & 340,0 & 150,6 & 0,4430 & 189,4 & 55,7 & 2,66 & 36,84 \\
\hline \multicolumn{2}{|c|}{ Soma do terço superior } & 266,3 & 118,7 & 0,4460 & 147,6 & 55,4 & 2,20 & 27,71 \\
\hline
\end{tabular}

A Tabela 1 também apresenta, em massa e percentagem, o quanto da massa fresca de ervamate pode ser encontrado em função dos terços (inferior, médio e superior) e orientação geográfica (norte, sul, leste, oeste). Verificou-se, em média, que $35,45 \%$ das folhas encontram-se no terço inferior, $36,84 \%$ no terço médio e $27,71 \%$ no terço superior. Referente à orientação geográfica, verificou-se que, em média, $31,87 \%$ das folhas encontram-se na orientação norte, $22,54 \%$ no sul, $20,84 \%$ no leste e $24,75 \%$ no oeste.

A relação percentual da massa fresca média das folhas de erva-mate em função dos terços das plantas (Tabela 1) é importante, pois pode auxiliar na quantificação da massa fresca retirada mediante a atividade de poda e, conseqüentemente, na quantificação dos nutrientes exportados.

A Tabela 2 e a Figura 2 apresentam os teores dos nutrientes ( $\mathrm{N}, \mathrm{P}, \mathrm{K}, \mathrm{Ca}$ e $\mathrm{Mg}$ ) das plantas de erva-mate analisadas, conforme os terços e a orientação geográfica. Não foi constatada diferença significativa quanto aos teores avaliados entre os terços e orientações. De forma geral, os nutrientes se comportaram como descrito por EPSTEIN e BLOOM (2004), onde aqueles que apresentam alta mobilidade, como o $\mathrm{N}, \mathrm{P}, \mathrm{K}, \mathrm{Mg}$, entre outros, se distribuem em teores semelhantes nos diversos compartimentos da planta. 
TABELA 2 - Teores dos nutrientes (N, P, K, Ca e Mg) obtidos das três plantas de erva-mate analisadas no experimento, conforme a orientação geográfica (norte, sul, leste e oeste) e terços (inferior, médio e superior).

\begin{tabular}{|c|c|c|c|c|c|c|c|}
\hline Amostra & Orientação & Terço & $\bar{N}$ & $P$ & $\begin{array}{c}\mathrm{K} \\
\left.\mathrm{kg}^{-1}\right)\end{array}$ & $\mathrm{Ca}$ & $\mathrm{Mg}$ \\
\hline \multirow{12}{*}{ Planta I } & \multirow{3}{*}{ Norte } & Inferior & 12,60 & 0,69 & 14,91 & 4,40 & 3,10 \\
\hline & & Médio & 16,00 & 0,73 & 18,52 & 3,50 & 2,80 \\
\hline & & Superior & 15,30 & 0,73 & 15,34 & 3,30 & 2,00 \\
\hline & \multirow{3}{*}{ Sul } & Inferior & 19,70 & 0,73 & 18,02 & 4,00 & 2,70 \\
\hline & & Médio & 21,30 & 0,63 & 15,95 & 4,30 & 3,20 \\
\hline & & Superior & 15,50 & 0,75 & 15,90 & 2,90 & 1,80 \\
\hline & \multirow{3}{*}{ Leste } & Inferior & 10,90 & 0,75 & 17,90 & 4,00 & 2,80 \\
\hline & & Médio & 14,90 & 0,69 & 16,88 & 3,80 & 2,80 \\
\hline & & Superior & 19,90 & 0,91 & 17,46 & 3,20 & 1,90 \\
\hline & \multirow{3}{*}{ Oeste } & Inferior & 12,10 & 0,59 & 16,98 & 5,00 & 4,10 \\
\hline & & Médio & 13,90 & 0,70 & 14,88 & 4,00 & 3,10 \\
\hline & & Superior & 15,70 & 0,69 & 15,00 & 4,30 & 3,20 \\
\hline \multirow{12}{*}{ Planta II } & \multirow{3}{*}{ Norte } & Inferior & 14,30 & 0,66 & 11,93 & 6,20 & 4,80 \\
\hline & & Médio & 16,60 & 0,86 & 14,30 & 6,20 & 3,60 \\
\hline & & Superior & 21,10 & 0,77 & 12,98 & 5,35 & 3,80 \\
\hline & \multirow{3}{*}{ Sul } & Inferior & 14,30 & 0,74 & 11,47 & 5,40 & 3,20 \\
\hline & & Médio & 32,60 & 0,83 & 11,05 & 4,30 & 2,50 \\
\hline & & Superior & 21,30 & 0,84 & 14,12 & 4,20 & 2,30 \\
\hline & \multirow{3}{*}{ Leste } & Inferior & 16,60 & 0,82 & 11,22 & 6,45 & 3,15 \\
\hline & & Médio & 27,60 & 0,85 & 11,96 & 4,95 & 3,05 \\
\hline & & Superior & 17,60 & 0,88 & 11,63 & 5,10 & 3,50 \\
\hline & \multirow{3}{*}{ Oeste } & Inferior & 27,00 & 0,79 & 13,35 & 5,20 & 3,50 \\
\hline & & Médio & 16,70 & 0,73 & 13,30 & 3,80 & 2,20 \\
\hline & & Superior & 17,80 & 0,93 & 15,10 & 4,40 & 2,90 \\
\hline \multirow{12}{*}{ Planta III } & \multirow{3}{*}{ Norte } & Inferior & 21,80 & 0,83 & 14,95 & 6,30 & 4,20 \\
\hline & & Média & 22,50 & 0,81 & 17,65 & 4,90 & 2,50 \\
\hline & & Superior & 20,90 & 1,01 & 16,83 & 3,80 & 2,30 \\
\hline & \multirow{3}{*}{ Sul } & Inferior & 19,90 & 0,79 & 13,65 & 6,00 & 4,30 \\
\hline & & Média & 20,80 & 0,77 & 15,13 & 4,50 & 3,00 \\
\hline & & Superior & 21,90 & 1,09 & 16,96 & 3,30 & 2,80 \\
\hline & \multirow{3}{*}{ Leste } & Inferior & 16,20 & 0,78 & 16,76 & 5,10 & 3,10 \\
\hline & & Média & 17,60 & 0,74 & 15,56 & 7,10 & 4,60 \\
\hline & & Superior & 21,50 & 1,22 & 17,68 & 3,50 & 2,10 \\
\hline & \multirow{3}{*}{ Oeste } & Inferior & 21,10 & 0,91 & 14,53 & 4,70 & 3,00 \\
\hline & & Média & 19,90 & 0,85 & 15,14 & 3,50 & 2,20 \\
\hline & & Superior & 22,00 & 1,38 & 16,71 & 3,30 & 2,50 \\
\hline \multirow{3}{*}{\multicolumn{2}{|c|}{$\begin{array}{l}\text { Média das plantas e } \\
\text { orientações }\end{array}$}} & Inferior & 17,21 & 0,76 & 14,64 & 5,23 & 3,50 \\
\hline & & Média & 20,03 & 0,77 & 15,03 & 4,57 & 2,96 \\
\hline & & Superior & 19,21 & 0,93 & 15,48 & 3,89 & 2,59 \\
\hline \multicolumn{2}{|c|}{ Média Geral } & & 18,82 & 0,82 & 15,05 & 4,56 & 3,02 \\
\hline
\end{tabular}

A Tabela 3 apresenta a análise de variância (ANOVA) para o $\mathrm{Ca}$, considerando os tratamentos em parcelas subdivididas. Os tratamentos identificados com as letras " $A$ " referem-se aos terços e "B" a orientação geográfica, considerando-se a altura como a variável principal. A ANOVA revelou efeito significativo $(p<0,05)$ apenas para o tratamento $A$, no entanto, para os efeitos do tratamento $B$, bloco e interação $A \times B$, não foi constatada diferenças significativas.

O teor de $\mathrm{Ca}$ não apresentou diferença estatística entre os terços da planta ao considerar o nível de $1 \%$ de probabilidade de erro. No entanto, foi constatada diferença significativa $(p<0,05)$ em relação ao teor existente no terço superior. Quanto ao terço médio, não existiu diferença significativa em relação aos demais (Tabela 4). Desta forma, existiu diferença entre as médias de exportação do referido nutriente, em pelo menos uma das porções da altura. Este comportamento pode ter ocorrido devido às características do nutriente, pois, segundo diversos autores (LARCHER, 2000; TAIZ e ZEIGER, 2004; EPSTEIN e BLOOM, 2004), o Ca apresenta pouca mobilidade na planta devido a sua grande imobilização na parede celular e no floema, principalmente na forma de oxalato de cálcio. Além disso, devido à função do $\mathrm{Ca}$ na planta ser principalmente estrutural, sua translocação para tecidos mais jovens é reduzida. 
SOUZA, J.L.M. et al. Teores de nutrientes foliares em plantas...

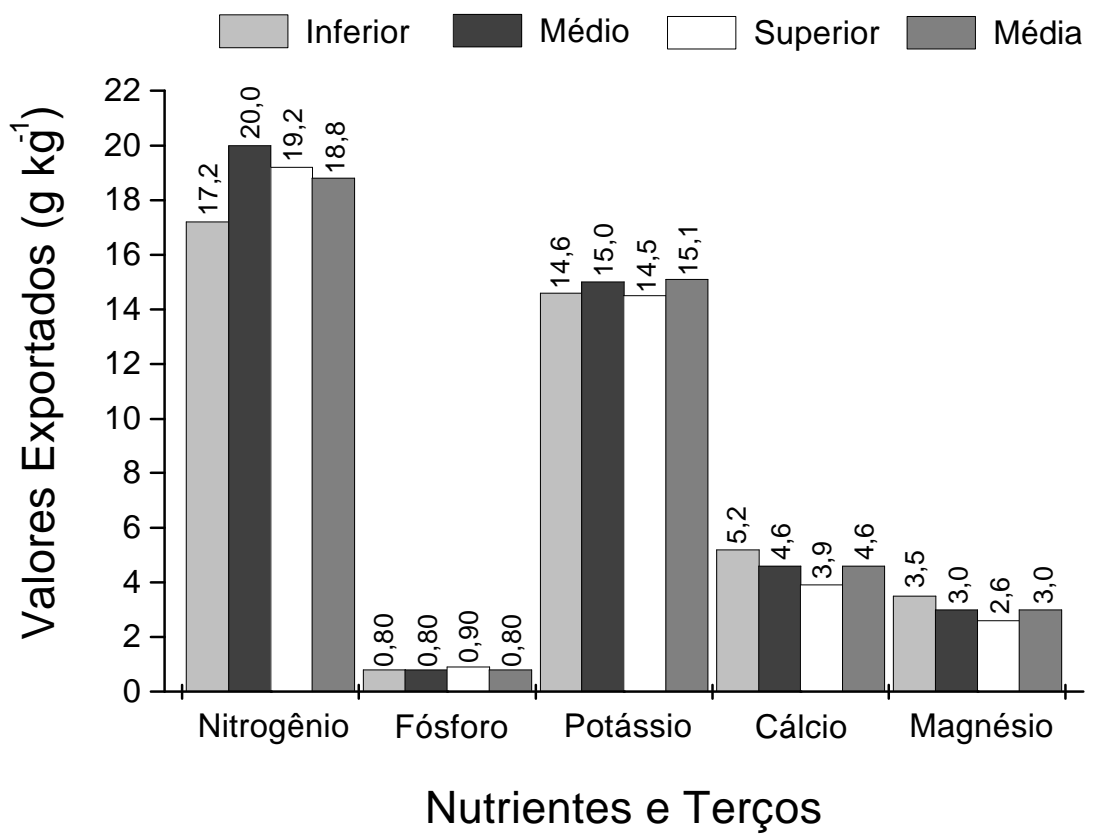

FIGURA 2 - Teores foliares médios dos nutrientes $\mathrm{N}, \mathrm{P}, \mathrm{K}, \mathrm{Ca}$ e $\mathrm{Mg}$, exportados por kg de matéria seca, em função dos terços inferior, médio e superior de plantas de erva-mate.

TABELA 3 - Análise de variância, com os tratamentos em parcelas subdivididas, para o Cálcio (Ca).

\begin{tabular}{lcccccc}
\hline \multicolumn{1}{c}{ Causas de Variação } & $\mathrm{GL}$ & $\mathrm{SQ}$ & $\mathrm{QM}$ & $\mathrm{F}_{\mathrm{c}}$ & $\mathrm{F}_{5 \%}$ & $\mathrm{~F}_{1 \%}$ \\
\hline Tratamento A (terço da altura) & 2 & 10,80 & 5,40 & 7,75 & 6,94 & 18,00 \\
Bloco & 2 & 9,38 & 4,69 & 6,73 & 6,94 & 18,00 \\
Erro & 4 & 2,79 & 0,70 & - & - & - \\
\hline Parcelas & 8 & 22,97 & 2,87 & - & - & - \\
\hline Tratamento B (orientação geográfica) & 3 & 2,86 & 0,95 & 1,60 & 3,16 & 5,09 \\
Interação A x B & 6 & 2,50 & 0,42 & 0,70 & 2,66 & 4,01 \\
Erro & 18 & 10,77 & 0,60 & - & - & - \\
\hline Total & 35 & 39,11 & 1,12 & - & - & - \\
\hline
\end{tabular}

Coeficientes de variação (CV): $18,29 \%$ no tratamento A e 16,95\% no tratamento B.

$\mathrm{GL}=$ grau de liberdade, $\mathrm{SQ}=$ soma de quadrados, $\mathrm{QM}=$ quadrado médio, $\mathrm{F}_{\mathrm{c}}=$ valor de $\mathrm{F}$ calculado

$\mathrm{F}_{5 \%}=$ valor de $\mathrm{F}$ tabelado para probabilidade de $5 \%, \mathrm{~F}_{1 \%}=$ valor de $\mathrm{F}$ tabelado para probabilidade de $1 \%$.

TABELA 4 - Teste de comparação de médias por Duncan, ao nível de 1\% e 5\% de probabilidade de erro, para o $\mathrm{Ca}$, em função dos terços da altura de plantas de llex paraguariensis.

\begin{tabular}{|c|c|c|c|c|}
\hline \multirow{2}{*}{$\begin{array}{l}\text { Porção da Altura } \\
\text { Terço Inferior }\end{array}$} & \multicolumn{2}{|c|}{$\begin{array}{l}\text {----o probabilidade } \\
\end{array}$} & \multicolumn{2}{|c|}{$5 \%$ de probabilidades } \\
\hline & 5,229167 & $\mathrm{a}$ & 5,229167 & $\mathrm{a}$ \\
\hline Terço Médio & 4,570833 & $\mathrm{a}$ & 4,570833 & $a b$ \\
\hline Terço Superior & 3,8875 & $\mathrm{a}$ & 3,8875 & $b$ \\
\hline
\end{tabular}

* Nas colunas, fatores com a mesma letra não apresentam diferença estatística. 
$\mathrm{Na}$ análise de variância para o $\mathrm{N}$ e K, verificou-se que o valor $\mathrm{F}$ calculado não apresentou diferença significativa a $5 \%$ de probabilidade de erro nos tratamentos e interação AxB. No entanto, apresentou diferença significativa a $5 \%$ e $1 \%$, respectivamente, entre os blocos, ou seja, em pelo menos uma das três plantas. $\mathrm{Na}$ análise de variância para o $\mathrm{P}$ e $\mathrm{Mg}$, foi observado que o valor $\mathrm{F}$ calculado não apresentou diferença significativa a $5 \%$ de probabilidade de erro nos tratamentos, blocos e interação AxB.

Como não houve diferença significativa nos tratamentos e interação $A \times B$, não foi necessário realizar o teste de comparação das médias. Desta forma, estatisticamente, não existe motivo para suspeitar que as plantas de erva-mate analisadas no experimento exportem diferentes quantidades de $\mathrm{N}, \mathrm{K}, \mathrm{P}$ e Mg, em função dos terços (tratamento A) e orientação geográfica (tratamento $\mathrm{B}$ ).

Para as médias dos nutrientes em relação aos terços (Tabela 2), observou-se que o $\mathrm{N}$ apresentou teores dentro do esperado. Diversos trabalhos (REISSMANN et al., 1997; RACHWAL et al., 2000; PANDOLFO et al., 2003; BORILLE, 2004; RAKOCEVICZ et al., 2006; OLIVA, 2007) mostram que os teores de $\mathrm{N}$ em erva-mate podem variar de $17,2 \mathrm{~g} \mathrm{~kg}^{-1}$ a $31,50 \mathrm{~g} \mathrm{~kg}^{-1}$, dependendo da espécie, época, juvenilidade do material, localidade, entre outros. Ocorreu uma tendência dos maiores teores de $\mathrm{N}$ nos terços médio $\left(20,03 \mathrm{~g} \mathrm{~kg}^{-1}\right)$ e superior $\left(19,21 \mathrm{~g} \mathrm{~kg}^{-1}\right)$, indicando que a presença deste nutriente é mais freqüente nas folhas mais jovens. Os teores de $\mathrm{N}$ diminuem à medida que as folhas ficam mais próximas do estado de senescência (terço inferior: $17,21 \mathrm{~g} \mathrm{~kg}^{-1}$ ). Este fato ocorre devido à alta mobilidade do $\mathrm{N}$, que permite a sua translocação das folhas mais velhas para ser reutilizado nas folhas mais novas (RAIJ, 1991; EPSTEIN e BLOOM, 2004).

O P apresentou teores que vão de acordo com os trabalhos de REISSMANN et al. (1999) e RACHWAL et al. (2000), que observaram teores de 0,5 a $3,2 \mathrm{~g} \mathrm{~kg}^{-1}$ e 0,82 a $0,94 \mathrm{~g} \mathrm{~kg}^{-1}$, respectivamente, para as médias dos nutrientes (Tabela 2 ) em relação aos terços inferior $\left(0,76 \mathrm{~g} \times \mathrm{kg}^{-1}\right)$, médio $\left(0,77 \mathrm{~g} \mathrm{~kg}^{-1}\right)$

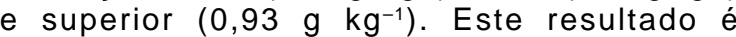
conseqüência do fato do $\mathrm{P}$ ser um nutriente de alta mobilidade, sendo facilmente redistribuído a partir de órgãos mais velhos para órgãos em expansão (LARCHER, 2000; MALAVOLTA, 1980).

CALDEIRA (1998) comenta que o $P$ é o único elemento que possui elevada eficiência de utilização nas florestas tropicais, principalmente em áreas onde ele se encontra em baixos teores. Para a localidade de estudo, a interpretação dos resultados da análise de solo para $\mathrm{O}$, conforme COMISSÃO DE FERTILIDADE DO SOLO - RS/SC (2004) classificou o teor deste elemento como muito baixo. Os níveis deste elemento nos solos do Brasil geralmente são baixos e, portanto, a demanda de abastecimento pode estar relacionada à oferta proporcionada pela matéria orgânica, enriquecida pela deposição de material vegetal ou biomassa (MENDES, 1996). Os níveis de $\mathrm{P}$ em solos são comprometidos pelos baixos valores de $\mathrm{pH}$ e altas concentrações de alumínio, o que diminui a disponibilidade deste mineral (MALAVOLTA e KLIEMANN, 1985; LEITÃO, 1998).

Os teores de $\mathrm{K}$ encontrados nos terços inferior $\left(14,64 \mathrm{~g} \mathrm{~kg}^{-1}\right)$, médio $\left(15,03 \mathrm{~g} \mathrm{~kg}^{-1}\right)$ e superior $\left(15,48 \mathrm{~g} \mathrm{~kg}^{-1}\right)$ ficaram de acordo com o intervalo 11,5 a $16,2 \mathrm{~g} \mathrm{~kg}^{-1}$ encontrado por RACHWAL et al. (2000). Os teores semelhantes nos diferentes terços da planta indicam que este elemento é altamente móvel no floema. Sua utilização geralmente é eficiente no sentido de ser prontamente redistribuído das folhas para órgãos mais novos (LARCHER, 2000; MALAVOLTA, 1980).

A maior parte do $\mathrm{K}$ é absorvida pelas plantas durante os estádios iniciais de desenvolvimento (MEURER, 2006), pois este tem papel fundamental na fotossíntese e síntese de carboidratos (BRITO et al., 2006). Assim, visto que o $\mathrm{K}$ é redistribuído para órgãos em crescimento, à medida que a planta se desenvolve, sugere-se ocorrer grande translocação deste elemento das folhas e ramos para as flores; sendo uma preparação da planta para a fase subseqüente à produção dos frutos (LEITÃO, 1998).

Os maiores teores de $\mathrm{Mg}$ foram verificados nos terços inferior $\left(3,50 \mathrm{~g} \mathrm{~kg}^{-1}\right)$ e médio $\left(2,96 \mathrm{~g} \mathrm{~kg}^{-1}\right)$, respectivamente. No entanto, as diferenças observadas não foram estatisticamente superiores aos teores encontrados no terço superior $(2,59 \mathrm{~g}$ $\mathrm{kg}^{-1}$ ). RAIJ (1991) considera o Mg um elemento móvel na planta.

Com exceção do $\mathrm{Ca}$, as concentrações totais dos nutrientes obtidos nas folhas da erva-mate (Tabela 2) foram menores do que os encontrados por REISSMANN et al. (1985) em ervais nativos no Paraná. É conveniente observar que o trabalho desenvolvido por estes autores foi realizado em um erval nativo possuindo maior variabilidade por unidade de área.

É importante observar que na revisão bibliográfica foram encontrados poucos trabalhos envolvendo o estudo do teor médio $\left(\mathrm{g} \mathrm{kg}^{-1}\right)$ de macronutrientes para erva-mate. Desta forma, para uma comparação, a Tabela 5 traz os teores foliares médios de alguns macronutrientes $(\mathrm{N}, \mathrm{P}, \mathrm{K}, \mathrm{Ca}, \mathrm{Mg})$ das folhas, obtidos por outros autores que estudaram espécies do gênero Ilex.

$\mathrm{O}$ valor médio do teor foliar de $\mathrm{N}$ da ervamate do presente estudo $\left(18,82 \mathrm{~g} \mathrm{~kg}^{-1}\right)$ foi superior apenas ao valor médio do teor presente na ervamate procedência Ivaí analisada por OLIVA (2007), sendo inferior aos registrados nos demais trabalhos (Tabela 5). No entanto, é conveniente lembrar que a exportação de nutrientes por folhas de erva-mate pode variar dependendo da espécie, época, juvenilidade do material, localidade, entre outros. 
SOUZA, J.L.M. et al. Teores de nutrientes foliares em plantas...

TABELA 5 - Teores médios de macronutrientes foliares de llex.paraguariensis e de algumas espécies florestais.

\begin{tabular}{|c|c|c|c|c|c|c|}
\hline \multirow{2}{*}{ Espécie } & \multirow{2}{*}{ Local } & \multicolumn{5}{|c|}{ Teor de matéria seca $\left(\mathrm{g} \mathrm{kg}^{-1}\right)$} \\
\hline & & $\mathrm{N}$ & $\mathrm{P}$ & K & $\mathrm{Ca}$ & $\mathrm{Mg}$ \\
\hline Ilex paraguariensis do presente estudo & Guarapuava, PR & 18,82 & 0,82 & 15,05 & 4,56 & 3,02 \\
\hline $\begin{array}{l}\text { llex paraguariensis de ervais naturais } \\
\text { (CALDEIRA, 2003) }\end{array}$ & General Carneiro, PR & 25,58 & 1,17 & 16,04 & 8,03 & 4,93 \\
\hline $\begin{array}{l}\text { Ilex paraguariensis de ervais naturais } \\
\text { (REISSMANN et al., 1985) }\end{array}$ & Mandirituba, PR & 20,60 & 1,45 & 17,20 & 5,20 & 3,75 \\
\hline $\begin{array}{l}\text { Ilex paraguariensis procedência Ivaí de erval } \\
\text { com } 8 \text { anos de idade (OLIVA, 2007) }\end{array}$ & Ivaí, PR & 17,80 & 1,60 & 11,90 & 11,20 & 5,80 \\
\hline $\begin{array}{l}\text { llex paraguariensis procedência Barão de } \\
\text { Cotegipe de erval com } 8 \text { anos de idade } \\
\text { (OLIVA, 2007) }\end{array}$ & Ivaí, PR & 20,10 & 1,30 & 12,30 & 7,80 & 2,80 \\
\hline $\begin{array}{l}\text { Ilex paraguariensis de ervais com } 9 \text { anos de } \\
\text { idade (REISSMANN et al., 1985) }\end{array}$ & Teixeira Soares, PR & 23,90 & 1,10 & 14,85 & 6,35 & 5,45 \\
\hline $\begin{array}{l}\text { Ilex paraguariensis de ervais com } 12 \text { anos de } \\
\text { idade (REISSMANN et al., 1985) }\end{array}$ & Paranaguá, PR & 23,10 & 1,10 & 12,80 & 6,50 & 5,50 \\
\hline Média da floresta ** (CALDEIRA, 2003) & General Carneiro, PR & 21,90 & 1,38 & 10,30 & 9,26 & 3,28 \\
\hline
\end{tabular}

** Teores médios de macronutrientes nas folhas de 39 espécies amostradas por CALDEIRA (2003), em uma floresta tropical em General Carneiro-PR, em 2001.

Os teores encontrados para o $\mathrm{P}(0,82 \mathrm{~g}$ $\left.\mathrm{kg}^{-1}\right)$ e $\mathrm{Ca}\left(4,56 \mathrm{~g} \mathrm{~kg}^{-1}\right)$ ficaram abaixo dos teores encontrados em todos os trabalhos citados na Tabela 5. Este resultado sugere que o povoamento do presente estudo é pouco exigente com relação a estes elementos. Como o teor médio exportado de $\mathrm{Mg}$ da erva-mate do presente estudo $\left(3,02 \mathrm{~g} \mathrm{~kg}^{-1}\right)$ foi superior apenas ao teor médio registrado na ervamate procedência Barão de Cotegipe, analisada por OLIVA (2007), pode-se sugerir também que a ervamate é pouco exigente a este nutriente. Os valores de $\mathrm{Mg}$ exportados pela erva-mate ficaram próximos da exportação de nutriente da llex paraguariensis de povoamentos naturais $\left(3,75 \mathrm{~g} \mathrm{~kg}^{-1}\right)$ obtidos por REISSMANN et al. (1985) e da média da floresta $\left(3,28 \mathrm{~g} \mathrm{~kg}^{-1}\right)$ analisada por CALDEIRA (2003).

$\mathrm{O}$ teor médio foliar encontrado para o $\mathrm{K}$ $\left(15,05 \mathrm{~g} \mathrm{~kg}^{-1}\right)$ evidencia que a erva-mate do presente estudo é exigente a este nutriente, pois o teor encontrado ficou próximo aos registrados nas espécies mais exigentes $\left(16,04 \mathrm{~g} \mathrm{~kg}^{-1}\right.$ e $17,20 \mathrm{~g} \mathrm{~kg}^{-}$ $\left.{ }^{1}\right)$ presentes na Tabela 5, referentes aos trabalhos de CALDEIRA (2003) e REISSMANN et al. (1985), nos quais ambos analisaram povoamentos naturais de llex paraguariensis.

Ao comparar-se os valores médios dos teores de todos os macronutrientes analisados no presente estudo com os teores médios de macronutrientes nas folhas de 39 espécies florestais amostradas por CALDEIRA (2003), verificou-se, com exceção do $\mathrm{K}$, que eles foram inferiores, o que sugere que um povoamento da espécie avaliada no presente estudo é menos exigente em termos de nutrição que a Floresta Ombrófila Mista Montana analisada por este autor.

\section{CONCLUSÕES}

1) A relação média entre a massa seca e fresca das folhas de erva-mate apresentou resultados aproximadamente iguais. O valor médio da relação massa seca/fresca para os três terços ficou em 0,4463.

2) Em média, $35,45 \%$ das folhas de ervamate encontram-se no terço inferior, $36,84 \%$ no terço médio e $27,71 \%$ no terço superior.

3) Os teores totais dos nutrientes ( N, P, K, $\mathrm{Ca}$ e $\mathrm{Mg}$ ) obtidos nas folhas da erva-mate $\left(\mathrm{g} \mathrm{kg}^{-1}\right)$ foram, em média, menores do que os encontrados na literatura em ervais nativos do Paraná.

4) As plantas de erva-mate analisadas não exportam diferentes quantidades dos nutrientes $\mathrm{N}$, $\mathrm{P}, \mathrm{K}$ e $\mathrm{Mg}$ em relação à altura (terços) e orientação geográfica. Dos nutrientes analisados, o $\mathrm{Ca}$ foi o único elemento que possui maior teor nas folhas mais velhas (terço inferior) do que nas folhas mais novas (terço superior).

\section{REFERÊNCIAS}

1. ANDRAE, F.; KRAPFENBAUER, A. Distribuição de raízes finas do pinheiro bravo (Podocarpos lambertii) e do pinheiro brasileiro (Araucaria angustifolia). In: PESQUISAS AUSTRO-BRASILEIRAS (1973-1982), 1983, Santa Maria. Anais. Santa Maria: UFSM. 1983. p. 56-67.

2. BORILLE, A.M.W. Relação entre compostos fitoquimicos e o nitrogênio em morfotipos de erva-mate (llex paraguariensis St. Hil.). Curitiba, 2004. 109 f. Dissertação (Mestrado em Agronomia) - Setor de Ciências Agrárias, Universidade Federal do Paraná.

3. BREMER J.M. Determination of nitrogen in soil by the Kjedahl method. Journal of Agricultural Science. v. 55, p. 1133, 1960. 
4. BRITO, C.H.; OLIVEIRA, A.P.; ALVES, A.K.; DORNELES, C.S.M.; SANTOS, J.F.; NÓBREGA, J.P.R. Produtividade da batata-doce em função de doses de $\mathrm{K}_{2} \mathrm{O}$ em solo arenoso. Horticultura Brasileira. v. 24, n. 3, p. 320-323. 2006.

5. CALDEIRA, M.V.W. Determinação de biomassa e nutrientes em uma Floresta Ombrófila Mista Montanhosa em General Carneiro, Paraná. Curitiba, 2003. 176 f. Tese (Doutorado em Ciências Florestais) - Universidade Federal do Paraná.

6. CALDEIRA, M.V.W. Quantificação da biomassa e do conteúdo de nutrientes em diferentes procedências de acácia-negra (Acacia mearnsii De Wild.). Santa Maria, 1998. 96 f. Dissertação (Mestrado em Engenharia Florestal) - Universidade Federal de Santa Maria.

7. COMISSÃO DE FERTILIDADE DO SOLO - RS/SC. Manual de adubação e calagem para os Estados do Rio Grande do Sul e de Santa Catarina. 10. ed. Porto Alegre: Comissão de Química e Fertilidade do Solo - RS/SC, 2004.

8. EMBRAPA. Empresa Brasileira de Pesquisa Agropecuária. Manual de métodos de análise de solo. 2. ed. Rio de Janeiro: EMBRAPA, 1997. $212 \mathrm{p}$.

9. EMBRAPA. Empresa Brasileira de Pesquisa Agropecuária. Sistema brasileiro de classificação de solos. Brasília: CNPS, 1999. $412 \mathrm{p}$.

10. EPSTEIN, E.; BLOOM, A. Nutrição mineral de plantas: princípios e perspectivas. Tradução: Maria Edna Tenório Nunes. 2. ed. Londrina: Editora Planta, 2004. 403 p.

11. FOSSATI, L.C. Avaliação do estado nutricional e da produtividade da erva-mate (llex paraguariensis St. Hil.) em função do sítio e da dioicia. Curitiba, 1997. 113 f. Dissertação (Mestrado em Engenharia Florestal) Universidade Federal do Paraná.

12. GOMES, F.P. Curso de estatística experimental. Piracicaba: Livraria Nobel, 2000. 466 p.

13. LARCHER, W. Ecofisiologia vegetal. São Carlos: Rima Artes e Textos, 2000. 531 p.

14. LEITÃO, A.C. Nutrição mineral, fenologia e distribuição da população de Ouratea spectabilis (Mart.) Engl., em área de cerrado na reserva biológica de Mogi-Guaçu, SP. Rio Claro, 1998. 131 f. Dissertação (Mestrado) Instituto de Biociências, UNESP.

15. LOURENÇO, R.S.; MEDRADO, M.J.S.; DALZOTO, D.N. Efeito de níveis de potássio sobre a produção de ervamate (llex paraguariensis St Hil.) no município de Ivaí - PR. Colombo: EMBRAPA, 1997.16 p. (EMBRAPA-CNPF. Pesquisa em Andamento, 38).

16. MACCARI JÚNIOR, A. Análise do pré-processamento da erva-mate para chimarrão. Campinas, $2005.193 \mathrm{f}$. Tese (Doutorado em Engenharia Agrícola na Área de Concentração Tecnologia Pós-colheita) - Universidade Estadual de Campinas.

17. MALAVOLTA, E. Elementos de nutrição mineral de plantas. São Paulo: Agronômica Ceres, 1980. 251 p.

18. MALAVOLTA, E.; KLIEMANN, H.J. Desordens nutricionais no cerrado. Piracicaba: POTAFOS, $1985.136 \mathrm{p}$.

19. MENDES, J.A. Distribuição espacial, fenologia e compartimentação de três espécies de Qualea (Vochysiaceae) na reserva biológica de Mogi-Guaçu-SP. Rio Claro: UNESP, 1996. 201 f. Tese (Doutorado) Instituto de Biociências, UNESP.

20. MEURER, E.G. Potássio. In: FERNANDES, M.S. (Ed.). Nutrição mineral de plantas. Viçosa: SBCS, 2006. p. 281-298.

21. OLIVA, E.V. Composição química e produtividade de procedências e progênies de erva-mate (Ilex paraguariensis St. Hil.) cultivadas em Latossolo Vermelho distrófico no município de Ivaí - PR. Curitiba, 2007. 73 f. Dissertação (Mestrado em Ciências do Solo) - Universidade Federal do Paraná.

22. PANDOLFO, C.M.; FLOSS, P.A.; DA CROCE, D. M.; DITTRICH, R.C. Resposta da erva-mate (Ilex paraguariensis, St. Hil.) à adubação mineral e orgânica em Latossolo Vermelho aluminoférrico. Ciência Florestal, v. 13, n. 2, p. 37-45. 2003.

23. PERKIN ELMER. Analytical methods for atomic absorption spectrophotometry. Norwalk: Perkin Elmer Corporation, 1976. 476 p.

24. RACHWAL, M.F.G.; CURCIO, G.R.; DEDECEK, R.A.; NIETSCHE, K.; RADOMSKI, M.I. Influência da luminosidade sobre os teores de macronutrientes e taninos em folha de erva-mate. In: CONGRESSO SUL-AMERICANO DE ERVA-MATE, 2.; REUNIÃO TÉCNICA DA ERVA-MATE, 3, 2000, Porto Alegre. Anais. Porto Alegre: Comissão dos Organizadores, Universidade do Rio Grande do Sul, Fundação Estadual de Pesquisa Agropecuária, 2000. p. 417-420.

25. RAIJ, B. van. Fertilidade do solo e adubação. Piracicaba: Agronômica Ceres/POTAFOS, 1991. 343 p.

26. RAKOCEVICZ, M.; MEDRADO, M.J.S.; LUCAMBIO, F.; VALDUGA, T.A. Influência do sexo, da sombra e da idade da folhas no sabor do chimarrão. In: CONGRESO SUDAMERICANO DE LA YERBA MATE, 4. REUNIÓN TÉCNICA DE LA YERBA MATE, 4. EXPOSICIÓN DE AGRONEGOCIOS DE LA YERBA MATE, 2., 2006, Posadas. Conferencias, Mesas Redondas y Trabajos Científicos. Posadas: Instituto Nacional de la Yerba Mate, 2006. p. 31-36.

27. REISSMANN, C.B.; ROCHA, H.; KOELHLER, C.W.; CALDAS, R.L.S.; HILDEBRAND, E.E. Bioelementos em folhas e hastes de erva-mate (Ilex paraguariensis St. Hil.) sobre Cambissolos na região de Mandirituba-PR. Revista Floresta, v. 14, n. 2, p. 49-54, 1983.

28. REISSMANN, C.B.; KOEHLER, C.W.; ROCHA, H.O. da.; HILDEBRAND, E.E. Avaliação das exportações de macronutrientes pela exploração da erva-mate. In: SEMINÁRIO SOBRE ATUALIDADES E PERSPECTIVAS FLORESTAIS: Silvicultura da erva-mate (Ilex paraguariensis St. Hil.), 10., 1985, Curitiba. Anais. Curitiba: 1985. p. 128-139.

29. REISSMANN, C.B.; RADOMSKI, M.I.; QUADROS, R.M.B. Relação entre os teores totais e hidrossolúveis dos elementos $\mathrm{K}, \mathrm{Ca}, \mathrm{Mg}, \mathrm{Fe}, \mathrm{Mn}, \mathrm{Cu}, \mathrm{Zn}$ e Al em folhas de erva-mate (llex paraguariensis St. Hil.). Arquivos de Biologia de Tecnologia, v. 37, n. 4, p. 959-971, 1994.

30. REISSMANN, C.B.; PREVEDELLO, B.M.S.; QUADROS, R.M.B de; RADOMSKI, M.I. Production and foliar N, P, K, Ca and $\mathrm{Mg}$ levels in erva-mate (llex paraguariensis St. Hil.) related to increasing base saturation levels. Arquivos de Biologia e Tecnologia, v. 40, n. 1, p. 241-249, 1997.

31. REISSMANN, C.B.; RADOMSKI, M.I.; QUADROS, R.M.B. Chemical composition of Ilex paraguariensis St. Hil. Under different management conditions in seven localites of Paraná State. Brazilian Archives of Biology and Technology, v. 42, n. 2, p. 187-194, 1999

32. TAIZ, L.; ZEIGER, E. Fisiologia vegetal. 3. ed. Tradução de: Eliane Romanato Santarém. [et al.]. Porto Alegre: Artmed, 2004. 719 p. 
SOUZA, J.L.M. et al. Teores de nutrientes foliares em plantas...

33. TRANI, P.E.; HIROCE, R; BATAGLIA, O.C. Análise foliar: amostragem e interpretação. Campinas: Fundação Cargil, 1983. $18 \mathrm{p}$.

34. VAN DEN DRIESSCHE, R. Nutrient storage, retranslocation and relation ship of stress to nutrition. In: NUTRITION OF PLANTATION FOREST, 1984, London. Proceedings. London: Academic Press/Bowen, 1984. p. 181-209.

35. ZÖTTL, H.W. Diagnosis of nutritional disturbances in forst stands. In: INTERNATIONAL SYMPOSIUM ON FORESTION, 1973, Paris. Anais. Paris: Ministère de L'Agriculture, 1973. p. 75-95.

Recebido em 19/03/2007

Aceito em 07/12/2007 
